Rev. Saúde públ, S. Paulo

3(1) : 93-104, jun. 1969.

\title{
INFORMES SÔBRE O PROGRAMA DE ERRADICAÇÃO DA MALARIA DO ESTADO DE SÃO PAULO (1)
}

CORRÊA, R. de R. \& Alves, U. P. - Informes sôbre o programa de erradicação da malária do Estado de São Paulo. Rev. Saúde públ., S. Paulo, 3(1): 93-104, jun. 1969.

RESUMo - A experiência e os resultados obtidos em erradicação da malária pelo SEMPDC do Estado de São Paulo demonstraram que as medidas adotadas inicialmente e durante tôda a fase de ataque, foram adequadas de acôrdo com a extensão e situação epidemiológica de sua área malárica. No referente a fase de consolidação, foram sempre solucionados os problemas originados pela importação de casos e em algumas ocasiões, o restabelecimento da transmissão em pequenos focos. Atualmente, continua-se com o seguimento dos focos embora sejam inativos. O futuro do programa de erradicação da malária do Estado de São Paulo é favorável em virtude do progresso na cobertura total do programa de erradicação da malária federal. Também contribuirão para acelerar o desaparecimento dos casos de malária a cobertura com DDT em três ciclos anuais e a adoção do tratamento de cura radical "familiar" nas Ilhas situadas nos Rios Paraná e Grande, fronteiras com os Estados de Mato Grosso e Minas Gerais. Tendo em conta as possibilidades do Programa entrar em manutenção e solicitar à OMS em 1971 o Certificado de Malária Erradicada, serão aproveitados os anos de 1969 e 1970 para intensificar a busca de casos, a coordenação com os serviços de saúde, o estabelecimento de áreas de demonstração para integração dêsses serviços e a malária, e um aprimoramento das operações.

\section{I N T R O D U C $\mathbb{A} O$}

Os programas de erradicação da malária, de acôrdo com a OPAS/OMS, são divididos em 4 f fases:

a) Preparatória - delimitação da área malárica, reconhecimento geográfico, adestramento de pessoal e operações de logística ; b) Ataque (aplicação de inseticida sòmente ou com outras medidas) - Avaliação epidemiológica;

c) Consolidação - vigilância epidemiológica ;

d) Manutenção - integração nos serviços gerais de saúde pública.

Recebido para publicação em 24-2-1969.

(1) Trabalho apresentado ao XVII Congresso Brasileiro de Higiene, Salvador, Bahia, de 8 a 14 de dezembro de 1968.

(2) Do Serviço de Erradicação da Malária e Profilaxia da Doença de Chagas - São Paulo, Brasil. 
CORREA, R. de R. \& ALVES, U. P. - Informes sôbre o programa de erradicação da malária do Estado de São Paulo. Rev. Saude públ., S. Paulo, 3(1):93-104, jun. 1969.

O Estado de São Paulo estêve em fase preparatória em 1958 e 1959. A fase de ataque teve seu início em fevereiro de 1960. Em janeiro de 1965, após prévia avaliação realizada por pessoal internacional e estadual, foram suspensas as operações de rociado na grande maioria dos municípios do Estado. Durante os anos de 1967 e 1968, essas áreas, com rociado suspenso, entraram oficialmente em consolidação, após prévia avaliação feita por pessoal internacional, federal e estadual. O mapa apresentado mostra as áreas malárica (ataque e consolidação) e não malárica, localizando, ainda, as áreas de demonstração para integração do programa de malária nos serviços gerais de saúde.

0 Estado, inicialmente, foi dividido em 8 zonas. Desde janeiro de 1968 e de acôrdo com a política da nova regionalização realizada pelo Govêrno Estadual, o programa ficou dividido em 10 Regiōes que coincidem com as Regióes Administrativas do Estado. Em 1960, a área malárica apresentava uma extensão de 110.318 $\mathrm{km}^{2}$ com 477.165 casas e 1.951 .797 habitantes. Em 1968 estiveram em fase de ataque 25.734 casas, com 88.657 habitantes em $7.045 \mathrm{~km}^{2}$ e em fase de consolidação $132.430 \mathrm{~km}^{2}$ com 5.152 .236 habitantes. A área não malárica neste ano possui $108.423 \mathrm{~km}^{2}$ e 11.229 .542 habitantes.

Os gastos efetuados com a erradicação da malária, desde 1965 e destinados para 1969 são os seguintes: destinam à doença de Chagas, simúlidas (borrachudos), e ao Culex pipiens fatigans, e $40 \%$ à malária.

\section{2, E P I D E M I O L O G I A}

De 2 de fevereiro de 1960, quando se iniciou a fase de ataque, até 31 de agôsto de 1968, foram colhidas, global e quantitativamente, 2.295.796 lâminas de sangue, das quais $585.037(25,48 \%)$ com busca passiva (feita pelos Serviços Gerais de Saúde e colaboradores voluntários) e $1.710 .759(74,52 \%)$ com busca ativa (realizada por funcionários do Serviço).

De acôrdo com a Tabela 1 , verificamos que no primeiro ano da fase de ataque (1960), de 117.568 lâminas examinadas, resultaram $10.179(8,66 \%)$ positivas para plasmódios. Em 1961, de 208.500 amostras de sangue, resultaram positivas $7.276(3,49 \%)$. Nestes dois primeiros anos não foram feitas investigações de casos porque não se justificavam nesta fase inicial, principalmente em virtude de seu grande número. Em 1962, de 370.667 lâminas, foram positivas $3.689(1,00 \%)$. Nesse ano $\mathrm{e}$ nos dois seguintes houve uma considerável intensificação da busca de casos para confirmar a situação epidemiológica. E isto, com a finalidade de possibilitar a suspensão do rociado e a subseqüente entrada da campanha em consolidação. Verificou-se também um declínio ainda mais significativo do índice de lâminas positivas (ILP). Após a avaliação epidemiológica, a partir

$\begin{array}{ll}1965 & \text { NCr\$2.528.841,00 (60\% do orcamento do Serviço) } \\ 1966 & \text { NCr\$3.727.729,00 (50\% do orcamento do Serviç) } \\ 1967 & \operatorname{NCr} \$ 4.438 .155,00(43 \% \text { do orçamento do Serviço) } \\ 1968 & \text { NCr\$3.065.942,00 (40\% do orcamento do Serviço) } \\ 1969 & \text { NCr\$3.815.073,00 (37\% do orcamento do Servico) }\end{array}$

Para o ano de 1968 o orçamento da Secretaria da Saúde importou em NCr\$ 155.039.420,00 e o SEMPDC em NCr\$ $7.664 .855,00(4,94 \%)$, dos quais $60 \%$ se de 1965 e até agôsto de 1968, não houve variações significativas no total de lâminas colhidas, inclusive nos totais de positivas, cujo montante diminuiu notòriamente. 
CORREA, R. de R. \& ALVES, U. P. - Informes sôbre o programa de erradicação da malária do Estado de São Paulo. Rev. Saúde públ., S. Paulo, 3(1):93-104, jun. 1969.

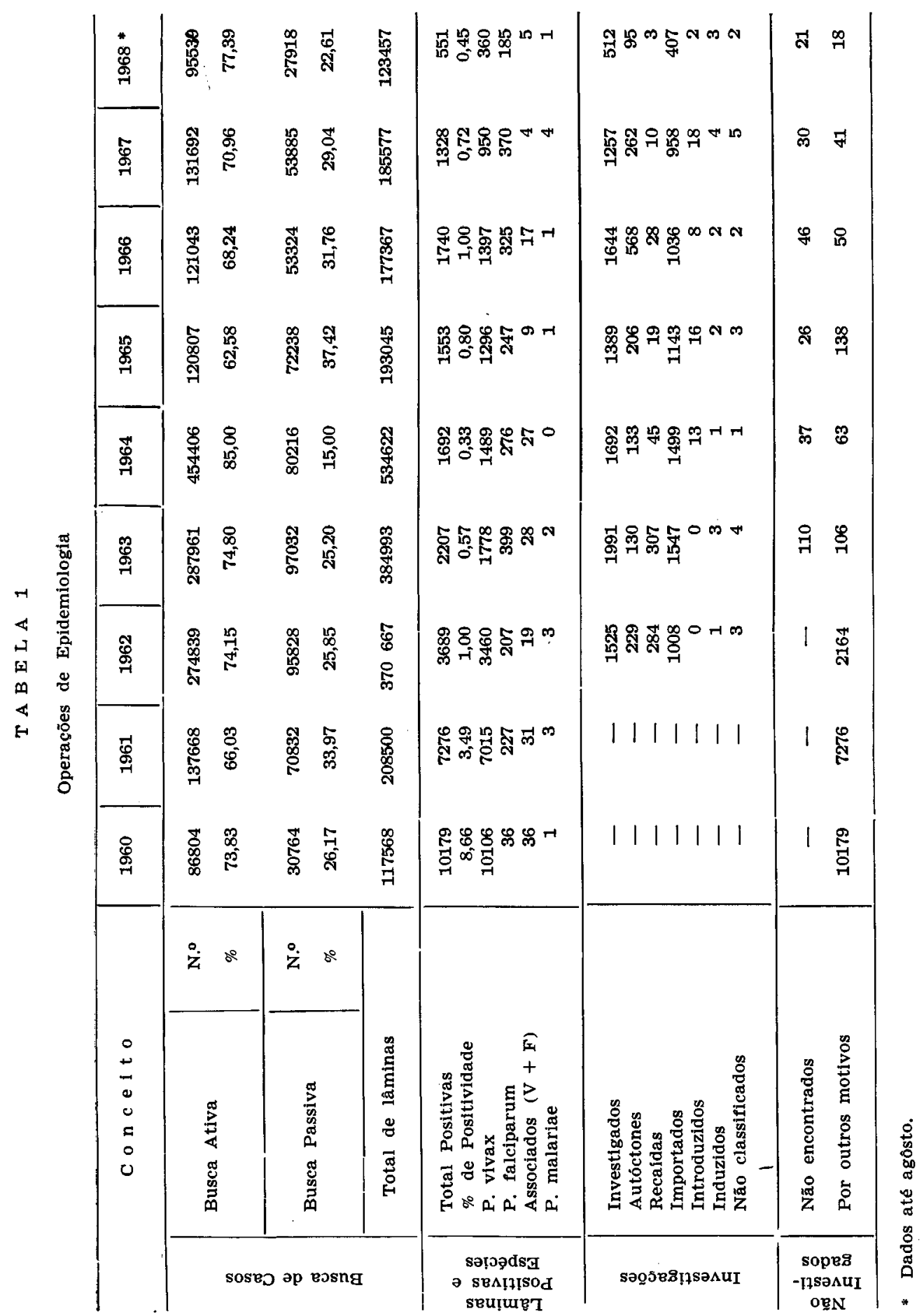


CORREA, R. đe R. \& ALVES, U. P. - Informes sôbre o programa de erradicaçáo da malária do Estado de São Paulo. Rev. Saúde puibl., S. Paulo, 3(1):93-104, jun. 1969.

Atualmente, o programa de São Paulo mantém ainda em fase de ataque pequenas áreas marginais que confinam com os Estados de Mato Grosso, Minas Gerais e Paraná. Estas já foram colocadas em cobertura completa pelo Govêrno Federal. com pirimetamina e sulfortomidina (sulfa de ação retardada) (Esquema III).

Para o estudo da eficiência da busca ativa e da busca passiva, na fase de consolidação (1967 e 1968 — até junho), verificamos o seguinte:

\begin{tabular}{|c|c|c|c|c|c|c|}
\hline \multirow{2}{*}{ Ano } & \multicolumn{2}{|c|}{ Busca Ativa } & \multicolumn{2}{|c|}{ Busca Passiva } & \multicolumn{2}{|c|}{ Tot a 1} \\
\hline & Lấminas & Casos & Lâminas & Casos & Lâminas & Casos \\
\hline 1967 & 131692 & 217 & 53885 & 1111 & 185577 & 1328 \\
\hline 1968 & 71739 & 52 & 21698 & 375 & 93437 & 427 \\
\hline
\end{tabular}

Isto fêz com que os casos importados diminuissem gradualmente. $E$ pois nessas áreas do Estado, ainda em ataque, que se evidencia a grande maioria dos casos autóctones. Em 1968, até agôsto, registraram-se no Estado, 95 casos classificados como autóctones, sendo dois da área não malárica, $39 \mathrm{em}$ consolidação e 54 em ataque. Os dois primeiros poderiam ser considerados como crípticos mas, como medida de precaução foram classificados como autóctones. Os 39 seguintes provêm de um foco de 17 casos e o restante está distribuído de maneira dispersa. Os 54 últimos são oriundos das faixas marginais limítrofes da área estadual.

Com referência aos casos de Plasmodium falciparum (= Laverania falcipara) autóctones e importados observa-se o seguinte:

\begin{tabular}{l|c|c}
\hline Ano & $\begin{array}{c}\text { Casos } \\
\text { autóctones }\end{array}$ & $\begin{array}{c}\text { Casos } \\
\text { importados }\end{array}$ \\
\hline 1965 & 28 & 218 \\
1966 & 17 & 325 \\
1967 & 32 & 342 \\
1968 (até agôsto) & 11 & 256 \\
\hline
\end{tabular}

Depois do tratamento clássico com $1.500 \mathrm{mg}$ de cloroquina em três dias, observou-se a recrudescência de casos de P. falciparum. Em vista disso, o Serviço adotou para todos êles, a medicação atual
O número de lâminas coletadas pela busca ativa é maior do que a passiva, entretanto, a quantidade de casos é bem menor, como se evidencia pela análise que se segue:

\begin{tabular}{l|c|c|c|c}
\hline \multirow{2}{*}{ Ano } & \multicolumn{2}{|c|}{ Lâminas } & \multicolumn{2}{c}{ Casos } \\
\cline { 2 - 5 } & \% B.A. & \% B.P. & \% B.A. & $\%$ B.P. \\
\hline 1967 & 71,0 & 29,0 & 16,3 & 83,7 \\
1968 & 78,8 & 23,2 & 12,2 & 87,8 \\
\hline
\end{tabular}

Uma vez mais fica demonstrado o grande valor da busca passiva. Como os serviços gerais de saúde executam êste tipo de busca, fizemos um resumo da sua participação nos anos de 1967 e 1968 (até junho) excluída a Região 1, a Grande São Paulo.

\begin{tabular}{c|c|c|c|c}
\hline Ano & $\begin{array}{c}\text { N.o } \\
\text { existentes }\end{array}$ & $\begin{array}{c}\text { N.o dos que } \\
\text { informaram }\end{array}$ & $\%$ & $\begin{array}{c}\text { N.o de } \\
\text { lâminas }\end{array}$ \\
\hline 1967 & 1177 & 432 & 36,7 & 8777 \\
1968 & 1209 & 338 & 27,9 & 2816 \\
\hline
\end{tabular}

A experiência do Programa de Erradicação da Malária do Estado de São Paulo, no referente aos Serviços Gerais de Saúde 
CORREA, R. de R. \& ALVES, U. P. - Informes sôbre o programa de erradicação da malária do Estado de São Paulo. Rev. Saúde puibl., S. Paulo, 3(1):93-104, jun. 1969.

demonstra que nos primeiros anos da fase de ataque, a participação foi maior que a atual. Na fase de consolidação o desaparecimento da malária ocasionou diminuição do interêsse; êste fato e a insuficiente motivação feita ao pessoal médico e para-médico dos serviços de saúde em níveis locais, explicariam a diminuição. de lâminas procedentes dêsses serviços.

A partir de 1965, após a avaliação já aludida, a evolução dos índices, nas áreas em consolidação foi a seguinte:

\begin{tabular}{l|l|l|l|l}
\hline Ano & IAES & ILP & IPA & $\begin{array}{c}\text { Casos } \\
\text { autóctones } \\
j 1000\end{array}$ \\
\hline 1965 & 2,9 & 0,5 & 0,15 & 0,006 \\
1966 & 2,8 & 0,7 & 0,19 & 0,06 \\
1967 & 1,9 & 0,2 & 0,05 & 0,008 \\
1968 (6 meses) & 1,2 & 0,3 & 0,04 & 0,007 \\
\hline
\end{tabular}

IAES (Indice anual de exames de sangue, ou seja, número de lâminas de busca ativa e busca passiva multiplicado por 100 e dividido pela população);

ILP (fndice de lâminas positivas, ou seja, número de casos multiplicado por $100 \mathrm{e}$ dividido pelo número de lâminas examinadas);

IPA (Incidência parasitária anual, ou seja, número de casos de malária multiplicado por 1000 e dividido pela população).

O IAES deve alcançar um mínimo de $10 \%$ ao ano. Como se verifica, os índices obtidos não satisfazem, mas deve ser levado em conta, que, para a obtenção do mesmo foi tomada em consideração a população direta e indiretamente protegida de cada município e não sòmente a que estêve em ataque. $O$ máximo tolerado para o IPA é de 0,1 por mil ao ano, que equivale a um caso de malária em 10.000 habitantes.

Os casos autóctones, em número insig. nificante em 1964 e 1965, 21 e 29 respectivamente, aumentaram nas áreas em fase de consolidação para 295 em 1966 devido a ocorrência de dois focos, sendo um no município de Angatuba - Região 4. (Sorocaba) com 84 casos de $P$. vivax e outro em São Vicente - Região 2 (São Paulo Exterior), com 117 casos de $P$. vivax e um de $P$. falciparum. As medidas tomadas consistiram na investigação epidemiológica, tratamento radical, intensificação da busca ativa com característica diária durante o primeiro mês, quinzenal no segundo e mensal nos posteriores. De imediato foi feito rociado focal que se repetiu uma segunda vez, sendo que desde aquela época até o presente, os citados focos continuam silenciosos e a busca de casos pode considerar-se aceitável. Em 1965, dos 29 casos autóctones mencionados anteriormente, 16 pertencem ao município de Flora Rica (Bairro do Formiga) Região 7 - Bauru, cujo foco, após as medidas tomadas, extinguiu-se. Em 1967, os 43 casos autóctones de áreas em consolidação corresponderam principalmente aos municípios de Peruibe - Região 2, Morro Agudo - Região 6, Sebastianópolis e Cosmorama da Região 8 e Ouro Verde - Região 7. Êles não originaram, em nenhuma ocasiáo, a introdução de outros e as medidas tomadas demonstraram ser oportunas. Atualmente, essas localidades continuam negativas. O município de Morro Agudo foi positivo em 1968, com dois casos ocorridos em duas localidades diferentes das de 1967.

De janeiro a junho de 1968 , dos 240 casos descobertos em áreas de consolidação, 39 foram classificados como autóctones, em 14 municípios e 17 localidades. Dêles, 17 pertenceram ao foco de Araçatuba, no qual o primeiro caso foi descoberto em abril pelo laboratório da Regiấo e os outros 16 pelo inquérito inicial. Como resultado das medidas postas em execução, deu-se o silenciamento dêsse foco.

Para tais trabalhos de epidemiologia, o Serviço dispõe de 4.694 postos de notificação, distribuídos pelos serviços gerais de saúde e colaboradores voluntários, 22 inspetores de epidemiologia, 126 visitadores rurais, 38 laboratórios, 44 microscopistas, 4 entomologistas e 9 auxiliares de entomologia; além de 23 veículos mo- 
CORREA, R. de R. \& ALVES, U. P. - Informes sôbre o programa de erradicação da malária do Estado de Săo Paulo. Rev. Saúde públ., S. Paulo, 3(1):93-104, jun. 1969.

torizados de 4 rodas e 4 barcos que atendem às áreas fluviais e marítimas.

Para a integração do programa de malária nos serviços gerais de saúde, o SEMPDC, em colaboração com a OPAS/ /OMS, selecionou duas áreas de demonstração (áreas pilôto) apoiados em critérios de seleção dos tipos: epidemiológico, ecológico, social, econômico e cultural. De acôrdo com a orientação da OPAS/OMS, apresentamos um esquema que esclarece o conceito de integração do programa de malária nos serviços de saúde, e sintetiza as atividades básicas em que serão adestrados os servidores de ambos os serviços e cuja execução contribuirá para a melhoria da infra-estrutura da saúde em áreas rurais. c) Estatística básica: informação sôbre nascimentos (data, lugar, sexo e nome da mãe) ; recomendação para inscrição no registro civil; informação sôbre óbitos;

d) Vulnerabilidade: proximidade de área malárica ou possibilidade de influxo freqüente de casos importados ou anofelinos infectados;

e) Receptividade: alta densidade de anofelinos vetores e a existência de fatôres climáticos ou ecológicos que favoreçam a transmissão;

f) Busca de casos: durante a fase de manutenção realiza-se, fundamentalmente, a busca passiva feita pela totalidade dos serviços de saúde. A busca ativa se efetua em condiçôes especiais.

\section{SERVICOS BASICOS DE SAOUDE}

“Áreas em Demonstração"

SAODE PUBLICA

Imunizações
Atencão à mãe e ao filho
Saneamento elementar
Educação para saúde
Primeiros socorros
Estatística básica

\section{ERRADICACÃO DA MALARIA}

Vulnerabilidade e Receptividade

Busca de Casos

Amostras de sangue

Diagnóstico microscópico

Tratamento de casos

Investigação de casos

\section{N T E G R A C A O}

Conceitos gerais sôbre alguns pontos já enumerados:

a) Atenção à mãe e ao filho: contrôle de curiosas com o censo, adestramento e fornecimento de material; canalização de parturientes e crianças aos serviços médicos; determinar casos de urgência (hemorragias e infecção puerperal);

b) Saneamento elementar: água de consumo e disposição de excretas;
Para a escolha das áreas de demonstração é necessário contar com o valioso auxílio da educação sanitária para "in loco" motivar a população e reunir os seguintes dados:

a) Informes gerais da área, com superfície, densidade demográfica e população;

b) Registro de morbidade das moléstias transmissíveis; 
CORREA, R. de R. \& ALVES, U. P. - Informes sôbre o programa de erradicação da malária do Estado de São Paulo. Rev. Saúde públ., S. Paulo, 3(1):93-104, jun. 1969.

c) Dados de mortalidade e causas de morte;

d) Dados de busca de casos de malária;

e) Dados sôbre aplicação de inseticida;

f) Recursos da área, dos serviços de saúde e do programa de malária.

\section{TER A P U T I C A}

Os esquemas de tratamento de malária, adotados pelo SEMPDC são em número de 5, apresentados em anexo:

I - Tratamento presuntivo (quando da coleta da lâmina de sangue);

II - Tratamento de cura radical das infecções a $P$. vivax e $P$. malariae;

III - Tratamento de cura radical das infecções por $P$. falciparum;

IV - Tratamento de cura radical das infecções por $P$. falciparum, em casos de recrudescências após utilização do esquema III;

V - Tratamento do coma malárico.

Todos os medicamentos utilizados são fornecidos pela OPAS/OMS. Com base em publicações da Campanha de Erradicação da Malária Federal ${ }^{1}$ (1968) usam-se para a proteção das pessoas que se dirigem às áreas com transmissão de malária, a cloroquina ou amodiaquina, em dose única semanal, sempre no mesmo dia, enquanto permanecem na área, da seguinte forma:

\section{Grupos Etários}

$$
\begin{aligned}
& 6 \text { a } 11 \text { meses } \\
& 1 \text { a } 2 \text { anos } \\
& 3 \text { a } 6 \text { anos } \\
& 7 \text { a } 11 \text { anos } \\
& 12 \text { a } 14 \text { anos } \\
& 15 \text { ou mais anos }
\end{aligned}
$$

O SEMPDC recomenda que se tome uma dose antes da ida para a zona malárica e mais uma dose semanal durante um mês após o regresso.

\section{4. $\mathrm{ENTOMOLOGIA}$}

No Brasil já foram descritas ou assinaladas 52 espécies de anofelinos. No Estado de São Paulo, de acôrdo com Alves \& DiAs JR. ${ }^{2}$ (1964) existem 2 gêneros, 7 subgêneros e 34 espécies às quais se pode acrescentar mais uma recentemente descrita por CoRrÊA \& RAMalho ${ }^{3}$ (1968). Durante a campanha de erradicação da malária (1960 a 1968, até agôsto) foram coletados 259.349 exemplares de larvas e adultos de anofelinos pertencentes a 23 espécies (Tabela 2).

T A B E L A 2 Espécies de Anofelinos capturadas no
Estado de São Paulo

(1960 a 1968 até agôsto)
A. albitarsis
A. a. domesticus
A. anchietai
A. aquasalis
A. argyritarsis
A. bellator
A. braziliensis
A. cruzii
A. darlingi
A. eiseni
A. galvãoi

A. intermedius

A. lutzi

A. maculipes

A. minor

A. noroestensis

A. owaldo $i$

A. parvus

A. rondoni

A. strodei

A. $t$. davisi

Chagasia fajardoi

Dessas 23 espécies, 5 são catalogadas como transmissoras da parasitose malárica: Anopheles (Kerteszia) bellator, A. (K.) cruzii, A. (Nyssorhynchus) albitarsis domesticus, A. (N.) aquasalis e A. (N.) darlingi. As 4 primeiras se distribuem pelo litoral e a última pelo planalto onde é considerada como o mais potente veiculador dessa plasmodiose. $\mathrm{O} A$. (K.) cruzii também transmite em alguns pontos do altiplano.

Em 366 provas de susceptibilidade dêsses vetores, ao DDT, realizadas nesse período, nenhum dêles mostrou resistência ao clorogenado. Com o $A$. strodei, o $A$. albitarsis e o $A$. galvãoi verificou-se tolerância de vigor.

Sendo já a área de consolidação do Estado muito extensa, os trabalhos entomológicos planejados para 1969 se basearão em localidades indicadores fixas (LF) 
CORREA, R. de R. \& ALVES, U. P. - Informes sôbre o programa de erradicação da malária do. Estado de Sáo Paulo. Rev. Saúde públ., S. Paulo, 3(1):93-104, jun. 1969.

que foram selecionadas para que sejam representativas. Com êsse objetivo adotaram-se os seguintes critérios:

1) Receptividade;

2) vulnerabilidade;

3) áreas nas quais os casos de malária tardaram mais tempo a desaparecer;

4) áreas onde a incidência foi mais alta;

5) áreas que apresentaram ou apresentam focos de maior ou menor importância.

Assim sendo, as localidades indicadoras fixas de entomologia foram designadas, preliminarmente, de acôrdo com os diferentes vetores. Foram as seguintes:

Area
Litoral sul
Litoral sul
Litoral centro
Planalto
Planalto
Planalto
Planalto
Planalto
Planalto
Planalto

Por motivos especiais foram selecionadas 3 localidades na área de ataque e uma na área não malárica (vide mapa).

\section{APLICACAO DE INSETICIDA}

$\mathrm{Na}$ Tabela 3 estão resumidos, por ciclos semetrais, os dados correspondentes às operaçōes de rociado. 0 inseticida utilizado tem sido o DDT na dose de dois gramas de grau técnico por $\mathrm{m}^{2}$ de superfície. 0 rendimento de casas por rociador/dia foi e está sendo na pequena área ainda em ataque, de 8,06 a 9,97. Até o presente não se registraram com êsses inseticidas sintomas de toxidez entre o pessoal que o tem manejado.

$\quad$ Localidade
Cananéia
Iguape
Vila Sónia
B.o do Formiga
Faz. União
Faz. Santana
Ilha do Bonito
Córrego Azul
Faz. Ramiro Murad
Ilha Solteira

Espé :les vetoras

A. belator e A. cruzii

A. a. domesticus

A. aquasalis

A. darlingi

A. darlingi

A. darlingi

A. darlingi

A. darlingi

A. darlingi

A. darlingi

T A B E L A 3

Operação de Roclado (1960 a 1968)

\begin{tabular}{|c|c|c|c|c|c|c|c|}
\hline Ciclos & $\begin{array}{c}\text { Localidades } \\
\text { trabalha- } \\
\text { das }\end{array}$ & $\begin{array}{c}\text { Casa } \\
\text { rociadas }\end{array}$ & $\begin{array}{c}\text { Casas } \\
\text { pendentes }\end{array}$ & $\begin{array}{c}\% \\
\text { pendentes }\end{array}$ & $\begin{array}{c}\text {-DDT- } \\
-100 \% \\
\text { por casa }\end{array}$ & $\begin{array}{c}\text { Casas por } \\
\text { homem/ } \\
\text { /dia }\end{array}$ & $\begin{array}{c}\text { Habitantes } \\
\text { diretamente } \\
\text { protegidos }\end{array}$ \\
\hline 1.0 & 9520 & 459281 & 17884 & 3,9 & 432,23 & 8,45 & 1951797 \\
\hline $2 .^{\circ}$ & 9530 & 459555 & 15957 & $\mathbf{3 , 5}$ & 403,90 & 9,60 & 1936085 \\
\hline 3.0 & 9167 & 436045 & 9335 & 2,2 & 416,40 & 9,50 & 1850214 \\
\hline 4.0 & 9075 & 431473 & 13007 & 3,0 & 414,80 & 9,79 & 1789061 \\
\hline 5.0 & 8255 & 380739 & 6673 & 1,7 & 419,10 & 9,68 & 1602444 \\
\hline $6 .^{\circ}$ & 8266 & 383717 & 8492 & 2,2 & 420,66 & 9,97 & 1615108 \\
\hline 7.0 & 7900 & 366817 & 9385 & 2,5 & 424,50 & 9,80 & 1496031 \\
\hline $8 .^{\circ}$ & 6799 & 316221 & 8063 & $\mathbf{2 , 5}$ & 433,30 & 9,54 & 1284405 \\
\hline 9.0 & 2193 & 110114 & 3356 & 3,0 & 443,60 & 8,06 & 443996 \\
\hline 10.0 & 2204 & 109480 & 3669 & 3,4 & 440,20 & 8,27 & 434974 \\
\hline 11.0 & 861 & 43313 & 2167 & 5,0 & 436,00 & 8,12 & 169854 \\
\hline 12.0 & 703 & 35766 & 2397 & 6,7 & 411,40 & 8,20 & 138459 \\
\hline $130^{\circ}$ & 654 & 33467 & 2386 & 7,2 & 404,90 & 8,10 & 126375 \\
\hline $14 .^{\circ}$ & 558 & 29923 & 2568 & 8,7 & 391,20 & 8,10 & 113878 \\
\hline $150^{\circ}$ & 563 & 27530 & 4165 & 15,2 & 407,00 & 8,10 & 100885 \\
\hline $16 .^{\circ}$ & 513 & 23910 & 1570 & 6,6 & 428,80 & 8,30 & 88657 \\
\hline
\end{tabular}

Area inicial de cobertura com inseticida: $110318 \mathrm{~km}^{2}$

Area de cobertura em 1968: $7045 \mathrm{~km}^{2}$ 
CORREA, R. de R. \& ALVES, U. P. - Informes sôbre o programa de erradicação da malária do Estado de São Paulo. Rev. Saúde públ., S. Paulo, 3(1):93-104, jun. 1969.

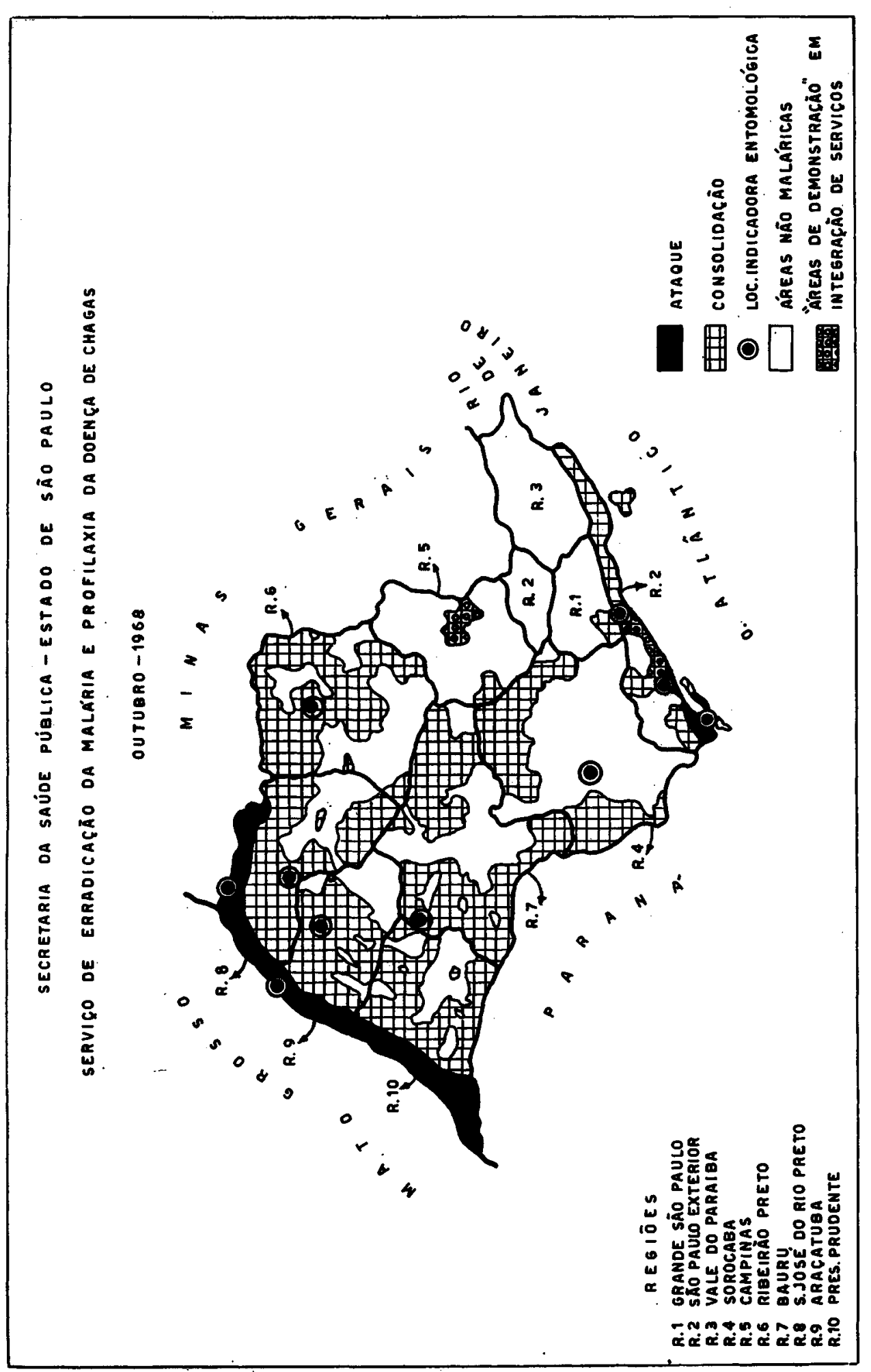


CORREA, R. de R. \& ALVES, U. P. - Informes sôbre o programa de erradicação da malária do Estado de São Paulo. Rev. Saúde públ., S. Paulo, 3(1):93-104, jun. 1969.

CorrêA, R. de R. \& Alves, U. P. - Report on the malaria erradication program, of the State of São Paulo, Brazil. Rev. Saúde pribl., S. Paulo, 3(1) :93-104, jun. 1969.

Summary - The experience and the results obtained in the Malaria Eradication Program by the Serviço de Erradicação da Malária e Profilaxia da Doença de Chagas (SEMPDC) in the State of São Paulo (Brasil) show that the measures of attack adopted, initially and during the whole attack phase, were adequate and according to the extension and epidemiologic situation of the malariogenic area. With reference to the consolidation phase, the problems originated by imported cases and in several occasions, re-establishment of transmission in small foci, were solved. At present the foci followup is being continued, even if considered inactive. The future of the Malaria Erradication Program in the State of São Paulo is favorable due to the progress in the total coverage of the Federal Malaria Eradication Program. The three anual spraying cycle of DDT as well as the adoption of the treatment of radical cure "Families" in the islands, situated on the Rio Paraná and Rio Gran- de, boderline with the state of Mato Grosso and Minas Gerais, much will contribute to accelarate the disappearance of malaria cases. Considering the possibilities of the Program to be transferred to the maintenance phase, and the Malaria Eradication Certificate beasked to the WHO in the year 1971, the years of 1969 and 1970 'will be used for an intensification of cases detection, coordination with Health Services, the establishing of areas of demonstration to the integration of these Services of Malaria, and in improvement of vigilance operations.

\section{REFERENCIAS BIBLIOGRAFICAS}

1. BRASIL - Campanha de Erradicação da Malária. Manual de terapêtica da malaria. Rio de Janeiro, 1968.

2. ALVES, U. P. \& DIAS Jr., J. - Alguns informes sôbre a malária e os anofelinos da Zona de Araçatuba, Estado de São Paulo, Brasil. (Diptera, Culicidae) Arq. Hig., S. Paulo, 29:221-234, dez. 1964.

3. CORREA, R. R. \& RAMALHO, G. R. Anopheles (Arribalzagia) anchietai sp.n. nova espécie de anofelino de São Paulo, Brasil (Diptera, Culicidae). Rev. bras. Malar., 20:115-132, jan./jun. 1968.

\section{ESQUEM A I}

Tratamento Presuntivo (quando da coleta da lamina de sangue)

Será dada dose única de cloroquina, ao ser feita a coleta da amostra de sangue, de a'ôrdo com a seguinte tabela:

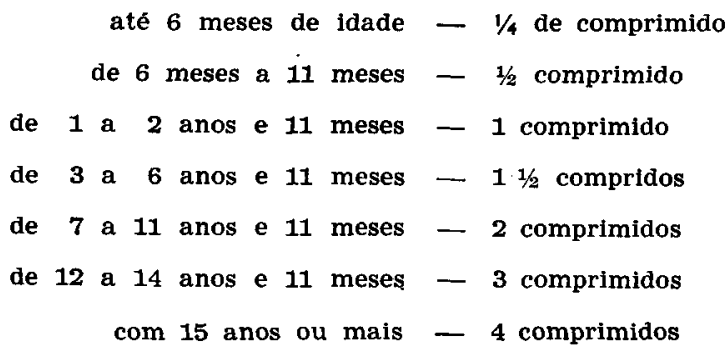

Em crianças de pequena idade, convém esmagar o comprimido e dar com água açucarada, ou leite condensado, para facilitar a administração, ou utilizar formulações em xarope. 
CORREA, R. de R. \& ALVES, U. P. - Informes sóbre o programa de erradicação da malária do Estado de São Paulo. Rev. Saúde públ., S. Paulo, 3(1):93-104, jun. 1969.

ES Q U E M A I I

Tratamento de Cura Radical das Infecç̃es a $P$. vivax e $P$. malariae Droga: N.o de comprimidos

\begin{tabular}{|c|c|c|c|c|}
\hline \multirow{2}{*}{ Grupos Etários } & \multicolumn{3}{|c|}{$\begin{array}{c}\text { Cloroquina (1) } \\
\text { (3 dias) }\end{array}$} & \multirow{2}{*}{$\begin{array}{c}\begin{array}{c}\text { Primaquina (2) } \\
\text { (14 dias) }\end{array} \\
\text { dosagem diária }\end{array}$} \\
\hline & 1.0 dia & 2.0 dia & $3 .^{\circ}$ dia & \\
\hline $\begin{array}{r}6 \text { meses a } 11 \text { meses } \\
1 \text { a } 2 \text { anos e } 11 \text { meses } \\
3 \text { a } 6 \text { anos e } 11 \text { meses } \\
7 \text { a } 11 \text { anos e } 11 \text { meses } \\
12 \text { a } 14 \text { anos e } 11 \text { meses } \\
\text { mais de } 15 \text { anos }\end{array}$ & $\begin{array}{l}1 / 2 \\
1 \\
1 \\
2 \\
3 \\
4\end{array}$ & $\begin{array}{c}1 / 2 \\
1 / 2 \\
1 \\
11 / 2 \\
2 \\
3\end{array}$ & $\begin{array}{c}1 / 2 \\
1 / 2 \\
1 \\
11 / 2 \\
2 \\
3\end{array}$ & $\begin{array}{ll}1 / 2 & \text { (infantil de } 5 \mathrm{mg} \text { ) (3) } \\
1 / 2 & \text { (infantil de } 5 \mathrm{mg} \text { ) } \\
1 & \text { (infantil de } 5 \mathrm{mg} \text { ) } \\
2 & \text { (infantil de } 5 \mathrm{mg}) \\
1 & \text { (adulto - 15 } \mathrm{mg} \text { ) } \\
1 & \text { (adulto }-15 \mathrm{mg} \text { ) }\end{array}$ \\
\hline
\end{tabular}

OBSERVACAO: Os 3 primeiros dias de primaquina coincidirăo com os 3 únicos dias de cloroquina. Para as crianças ate 6 meses de idade, administrar $1 / 4$ de comprimido de cloroquína (Aralen) de $150 \mathrm{mg}$ base, diàriamente e por 3 dias.

(1) 1 comprimido de cloroquina (Aralen) $=150 \mathrm{mg}$ de produto base.

(2) 1 comprimido (adulto) de primaquina (ICI) $=15 \mathrm{mg}$ de produto base.

(3) 1 comprimido (infantil) de primaquina (ICI) $=5 \mathrm{mg}$ de produto base.

ES Q U E M A I I I

Tratamento de Cura Radical das Infecçóes por $P$. falciparum

$\mathrm{Na}$ fase de consolidação, será utilizada a associação sulfortomidina (fanasulf) e pirimetamina (daraprim) de acôrdo com o seguinte esquema:

\begin{tabular}{|c|c|c|c|}
\hline \multirow{3}{*}{ Grupos Etários } & \multicolumn{2}{|c|}{1.0 dia } & \multirow{3}{*}{$\begin{array}{c}\begin{array}{c}2.0 \text { dia } \\
\text { só } \\
\text { Sulfortomidina }\end{array} \\
\begin{array}{c}\text { N.o de } \\
\text { comprimidos }\end{array}\end{array}$} \\
\hline & $\begin{array}{c}\text { Pirimetamina (1) } \\
\text { (daraprim) }\end{array}$ & $\begin{array}{l}\text { Sulfortomidina (2) } \\
\text { (fanasulf) }\end{array}$ & \\
\hline & $\begin{array}{l}\text { N.o de } \\
\text { comprimidos }\end{array}$ & $\begin{array}{l}\text { N.O de } \\
\text { comprimidos }\end{array}$ & \\
\hline $\begin{array}{rrr} & & 6 \text { a } 11 \text { meses } \\
1 \text { a } & 2 \text { anos e } 11 \text { meses } \\
3 & \text { a } & 6 \text { anos e } 11 \text { meses } \\
7 & \text { a } & 11 \text { anos e } 11 \text { meses } \\
12 & \text { a } 14 \text { anos e } 11 \text { meses } \\
\text { mais de } 15 \text { anos }\end{array}$ & $\begin{array}{c}1 / 2 \\
1 \\
11 / 2 \\
2 \\
2 \\
2\end{array}$ & $\begin{array}{c}1 / 4 \\
1 / 2 \\
3 / 4 \\
1 \\
11 / 2 \\
2\end{array}$ & $\begin{array}{l}1 / 4 \\
1 / 4 \\
1 / 2 \\
1 / 2 \\
3 / 4 \\
1\end{array}$ \\
\hline
\end{tabular}

OBSERVACAO: No caso de recrudescência após êste tratamento, repetí o mesmo esquema. Em nova recrudescéncia, após uso dos dois tratamentos com associação de pirimetamina e fanasulf, usar-se-á o esquema n.o IV.

Para as crianças ate 6 meses de idade, administrar $1 / 4$ de comprimido de cloroquina (Aralen) de $150 \mathrm{mg}$ base diariamente e por tres dias.

(1) 1 comprimido de Pirimetamina (daraprim) $=25 \mathrm{mg}$ de produto base.

(2) 1 comprimido de Sulfortomidina (fanasulf) $=500 \mathrm{mg}$ de produto base.

NOTA: A primaquina deve ser administrada após o 5.0 dia de tratamento da seguinte forma: 6 meses a 2 anos e 11 meses: $11 / 2$ compr. de $5 \mathrm{mg}$ (infantil) de uma só vez

3 a 6 anos e 11 meses: 1 compr. de $15 \mathrm{mg}$ (adulto) de uma só vez

7 a 11 anos e 11 meses: 2 compr. de $15 \mathrm{mg}$ (adulto) de uma só vez

12 anos ou mais: 3 compr. de $15 \mathrm{mg}$ (adulto) de uma só vez 
CORREA, R. de R. \& ALVES, U. P. - Informes sôbre o programa de erradicação da malária do Estado de São Paulo. Rev. Saúde públ., S. Paulo, 3(1):93-104, jun. 1969.

ES Q UE M A I V

Tratamento de Cura Radical das Infecções por $P$. falciparum, em casos de recrudescência após utilização do Esquema III

\begin{tabular}{|c|c|c|c|c|}
\hline \multirow{2}{*}{ Grupos Etários } & \multicolumn{2}{|c|}{$1.0 \mathrm{dia}$} & \multirow{2}{*}{$\frac{2.0 \text { dia }}{\text { Cloroquina }}$} & \multirow{2}{*}{$\frac{3.0 \text { dia }}{\text { Cloroquina }}$} \\
\hline & Cloroquina & Primaquina & & \\
\hline 6 meses a 11 meses & $1 / 2$ & $\begin{array}{c}11 / 2 \\
\text { (infantil) }\end{array}$ & $1 / 2$ & $1 / 2$ \\
\hline 1 a 2 anos e 11 meses & 1 & $\stackrel{2}{2}$ & $1 / 2$ & $1 / 2$ \\
\hline 3 a 6 anos e 11 meses & 1 & $\begin{array}{c}1 \\
\text { (adulto) }\end{array}$ & 1 & 1 \\
\hline 7 a 11 anos e 11 meses & $\mathbf{2}$ & $\stackrel{2}{\mathbf{2}}$ & $11 / 2$ & $11 / 2$ \\
\hline 12 a 14 anos e 11 meses & 3 & $\begin{array}{c}3 \\
\text { (adulto) }\end{array}$ & 2 & 2 \\
\hline mais de 15 anos & 4 & $\frac{\mathbf{3}}{\text { (adulto) }}$ & $\mathbf{3}$ & $\mathbf{3}$ \\
\hline
\end{tabular}

OBSERVAÇO: No caso de nova recrudescência após o uso déste esquema, usar-se-á sulfato ou cloridrato de quinino, na razão de $25 \mathrm{mg}$ por quilo de pêso, durante 10 dias sòmente.

No caso de se verificar que as formas assexuadas do parasito ainda persistem no sangue, após 5 dias de ter iniciado qualquer um dos esquemas indicados, isto é, esquemas III ou IV, dever-se-á administrar diàriamente $25 \mathrm{mg}$ por quilo de pêso, de sulfato ou cloridrato de quinino, porém durante 15 dias consecutivos.

Para as crianças até 6 meses de ldade, administrar $1 / 4$ de cloroquina (Aralen) de $150 \mathrm{mg}$ base diáriamente e por três dias.

\author{
E S Q U E M A V \\ Tratamento do Coma Malárico
}

1) No coma malárico, deve-se injetar, lentamente, durante 20 a $30 \mathrm{~min}$, por via endovenosa, cada $8 \mathrm{~h}$, até que o enfêrmo possa deglutir, $0,50 \mathrm{~g}$ de cloridrato de quinina ou bicloridrato de quinina, dissolvidos em 250 a $300 \mathrm{ml}$ de sôro glico-fisiológico; o plasma também serve de veículo ao quinino, facilitando o tratamento do choque anafilático e da anoxemia. Essas soluções, usadas endovenosamente, devem ser aquecidas a $37^{\circ} \mathrm{C}$ e aplicadas à razão de 30 a 40 gôtas por minuto.

2) Caso não possa ser felta venóclise, de imediato, aplicar o quinino (1) injetável intramuscular profunda (aproximadamente $8 \mathrm{mg}$ por quilo de péso ou seja, 0,50 $\mathrm{g}$ para um doente de $60 \mathrm{~kg}$ ), de $8 \mathrm{em} 8 \mathrm{~h}$, porém é importante fazer o tratamento do pré-coma ou coma.

3) Caso não disponha de quinino injetável, poderá ser usado, cloroquina (2) injetável, por via intramuscular ou venóclise, na razão de $5,8 \mathrm{mg}$ por quilo de pêso.

4) No caso de vómitos incoerciveis, sem coma, fazer o tratamento com quinino ou cloroquina, conforme esclarecido em 2 e 3 acima.

5) Caso não sejam possiveis as vias endovenosa ou intramuscular por motivo qualquer, usar o enema na razão de $500 \mathrm{mg}$ de quinino ( 1 comprimido), dissolvidos em $200 \mathrm{ml}$ de água ou sôro, aplicadas de $8 \mathrm{em} 8 \mathrm{~h}$, até que desapareça o coma, ou possa ser utllizada outra via. No caso de crianças, pode ser aplicada uma solução de quinino, $8 \mathrm{mg}$ por quilo de pêso, dissolvidos em $100 \mathrm{ml}$ de água.

6) Saindo o paciente do coma, usar o esquema especifico (esquemas Ir ou III).

(1) 1 ampola de quinino de $5 \mathrm{cc}=500 \mathrm{mg}$ de cloridrato de quinino

(2) 1 cc de cloroquina (Aralen) injetável $=40 \mathrm{mg}$ de produto base. 